\title{
Photography of the retinal nerve fibre layer: an optimised procedure
}

\author{
LARS FRISÉN \\ From the Department of Ophthalmology, University of Göteborg, Sweden
}

SUMMARY Normal and abnormal fundi were photographed at various magnifications in one and the same fundus camera, with and without 'red-free' filters and various types of black-and-white and colour films. Colour diapositive films were copied on various black-and-white negative films, with and without filters. The final negatives were evaluated under magnification with regard to resolution and contrast of detail in the nerve fibre layer. Complementary information was obtained by means of conventional resolution measurements at high and low contrast levels. The best overall results were obtained by copying colour slides obtained in unfiltered light on a new high-contrast black-and-white film (Kodak Technical Pan), with a Wratten No. 65 A filter. This simple technique produced negatives with a good definition of the nerve fibre layer, suitable as final records.

Photography of the peripapillary retinal nerve fibre layer has attracted considerable interest during recent years. In spite of the potential of this new diagnostic.technique, its universal application has been lagging. This is mainly due to the difficulties of visualising the faintly opaque nerve fibre bundles in ordinary fundus photographs. Maximum use of this technique therefore demands special quality control. Several reports have dealt with the optical properties of fundus cameras, ${ }^{1-4}$ focusing techniques, ${ }^{356}$ filters, ${ }^{7-11}$ films and developers, ${ }^{212} 13$ and printing procedures. ${ }^{14}$ However, a unifying study aiming to find optimum combinations has not yet appeared. It is the aim of the present report to fill this gap.

The overwhelming number of possible combinations of camera types, filters, films, and processing techniques makes a full permutation of variables practically impossible. This study was therefore limited to one modern camera, a single source of films and film developers, and a small number of carefully selected filters. Furthermore, this study concentrated on the production of optimum results in black-and-white. Colour materials are not only much more expensive than black-and-white materials but they are also more difficult to manipulate technically. The improved visibility of the retinal nerve fibre layer in green ('red-free') light also favours black-and-white documentation. ${ }^{7-11}$ Even

Correspondence to Dr L. Frisén, Ögonkliniken, Sahlgrenska sjukhuset, S-413 45 Göteborg, Sweden. with these restrictions more than 3000 photographs had to be evaluated in this study.

Numerous normal and abnormal fundi were photographed at various magnifications in one and the same fundus camera, with and without green filters, with various types of films and film developers. Complementary information was obtained by means of conventional resolution measurements at high and low contrast levels. Colour diapositive films were copied on various black-andwhite negative films, with and without green filters, with both photographic reproduction and contact copying. The final negatives were evaluated under high magnification with regard to resolution and contrast of detail in the nerve fibre layer. The best overall results were obtained by contact copying colour slides obtained in unfiltered light on a new high-contrast black-and-white film (Kodak Technical Pan), with green light. This simple technique produced negatives of very good definition of the nerve fibre layer, highly suitable as final records. The contrast was actually so high that direct printing on photographic paper led to image degradation. For good printing results unsharp masks proved to be valuable.

\section{Materials and methods}

The fundus camera used was an adapted Nikon Retinapan II. The original focusing screen was replaced by a full-format clear screen with a fine reticule pattern, and the original viewfinder was 
Table 1 Films and developers; manufacturer's data

\begin{tabular}{lcllll}
\hline Film name & Sensitivity & Graininess & Sharpness & $\begin{array}{l}\text { Resolving power } \\
\text { lines/mm at } \\
\text { high/low contrast }\end{array}$ & Developers \\
\hline Kodachrome 25 & 25 & Extremely fine (9) & High & $100 / 50$ & Kodak Laboratory \\
Kodachrome 64 & 64 & Extremely fine (10) & High & $100 / 50$ & Kodak Laboratory \\
Ektachrome 200 & 200 & Very fine (13) & High & $125 / 50$ & Kodak Laboratory \\
Panatomic-X & 32 & Extremely fine & Very high & $200 / 80$ & Microdol \\
Technical Pan & 100 & Extremely fine (8) & Not stated & $320 / 125$ & HC-110, D-19 \\
Plus-X Pan & 125 & Extremely fine & Very high & $125 / 50$ & Microdol, D-11 \\
Tri-X Pan & 400 & Fine & Very high & $100 / 50$ & Microdol
\end{tabular}

${ }^{1} \mathrm{RMS}$ granularity values given when available.

replaced with a Nikon DW-2 $6 \mathrm{X}$ viewfinder, to facilitate precise focusing. For critical focusing at the lowest magnification $(1.7 \times$, nominally), a $2 \times$ Galilean telescope was superposed on the viewfinder.

The camera was used both with and without magnification attachments. Two attachments were available: the original conversion tube (giving $5 \times$ magnification, nominally), and a Nikon TC-200 teleconverter (allowing nominal magnifications of $3.4 \times$ and $10 \times)$.

Resolution measurements were carried out as has been described previously. ${ }^{2}$ In brief, low-contrast and high-contrast NBS resolution charts were placed $1.5 \mathrm{~m}$ in front of the camera objective on its optical axis. The charts were photographed at various magnifications on different types of films. The DW-2 viewfinder was then replaced with a small $30 \times$ microscope, resting on the focusing screen. This served to ensure perfect focusing. Focus was adjusted for each new frame of film. After development the various films were evaluated at $40 \times$ in a stereo microscope. Resolving powers were calculated in lines per millimetre. ${ }^{15}$

Films and developers were all produced by Eastman Kodak Company. Three colour diapositive films of different sensitivity were included, namely, Kodachrome 25 and 64, and Ektachrome 200. Appropriate light-balancing filters were used in the resolution study. The black-and-white films included Tri-X Pan, Plus-X Pan, Panatomic-X, and Technical Pan (SO-115). The manufacturer's rating of various film properties is given in Table 1 together with information on the various development procedures. The black-and-white films were developed immediately after exposure, while the colour films were developed by a Kodak laboratory within a few days of exposure.

Copying of colour films on to black-and-white films was done both photographically and as a contact procedure. A Bowen's Illumitran served as the flashlight source for photographic copies. A Nikon F2 camera body combined with a clear focusing screen and a $30 \times$ focusing microscope was used together with several different types of objectives. These will be further described below. The reproduction scale was usually $1: 1$.

Contact copies were produced in a simple apparatus with tungsten light (Fig. 1). A $2.5 \mathrm{~mm}$ diameter aperture admitted light through a clear glass copying

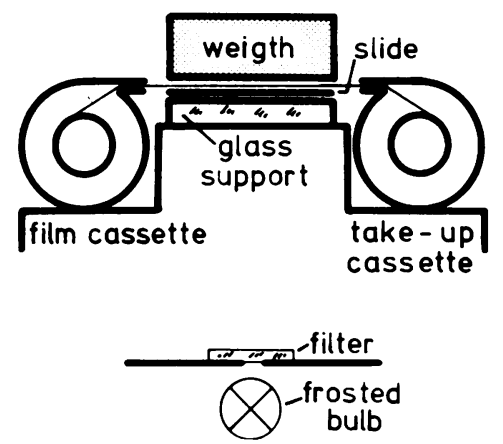

Fig. 1 Scheme of apparatus used for contact copying (not to scale). See text for details.

stage, which was placed $0.3 \mathrm{~m}$ from the aperture. Various filters could be interposed in the light beam. The slide to be copied was placed on the glass support, with the emulsion side up. In total darkness a suitable length of copying film was drawn out from its cassette and placed on top of the slide (emulsion side down). Registration was obtained by means of small knobs engaging the film perforations. A small weight pressed the film and the slide against the glass stage during exposure. The exposed portion of the film was then lifted off the stage and 
drawn into an empty cassette. The room light was then turned on, the slide changed, the light turned off, a new length of negative film drawn out, and so on.

Filters were used both in the fundus camera and during copying. They were selected to cover the most useful spectral range. ${ }^{7-11}$ A green Wratten filter of $26.2 \%$ transmittance (No. 40) was sometimes used in the fundus camera. A denser filter was used during copying, either a Wratten No. 65A (transmittance $6.2 \%$ ), or a medium bandwidth (spectral half-width $25 \mathrm{~nm}$ ) interference filter. Dominant wavelengths for the gelatin filters were $513.4 \mathrm{~nm}$ and $497.3 \mathrm{~nm}$ respectively. Maximum transmission for the interference filter occurred at $480 \mathrm{~nm}$.

Evaluation of image quality was made subjectively under 8-40 $\times$ magnification, attention being paid primarily to contrast, sharpness, and graininess. ${ }^{16}$ Except for the resolution measurement described above, most evaluations were carried out by ranking series of coded images. The code was not broken until 2 sequential rankings produced exactly the same results.

\section{Results}

Resolving powers were obtained for both high and low contrast levels for all films, at all magnification settings. The results are summarised in Fig. 2. The maximum number of resolved lines per millimetre was always considerably smaller than the resolving power indicated by the film manufacturer (cf. Table 1). Similar results have been reported for the Carl Zeiss fundus camera. ${ }^{2}$ These results indicate that the fundus camera seriously limits the resolution that can be obtained in fundus photography. The maximum number of lines per millimetre was obtained at the lowest magnification: as magnification attachments were added, resolution in terms of lines per millimetre in the film image went down. This effect was counteracted by a larger number of resolved line groups at higher magnifications.

The 2 slower colour slide films produced the best results throughout. It was usually impossible to tell the 2 films apart. The more rapid colour diapositive film produced consistently poorer results (Fig. 2).

Among the black-and-white films there was a very striking difference between Technical Pan on the one hand, and Plux-X Pan, and Tri-X Pan on the other (the VTE Pan film recommended by Frisén ${ }^{2}$ is no longer available). The former film produced pictures with considerably better resolution at both high and low contrast levels (Fig. 2). Technical Pan was developed in D-19 for $2 \mathrm{~min}$ at

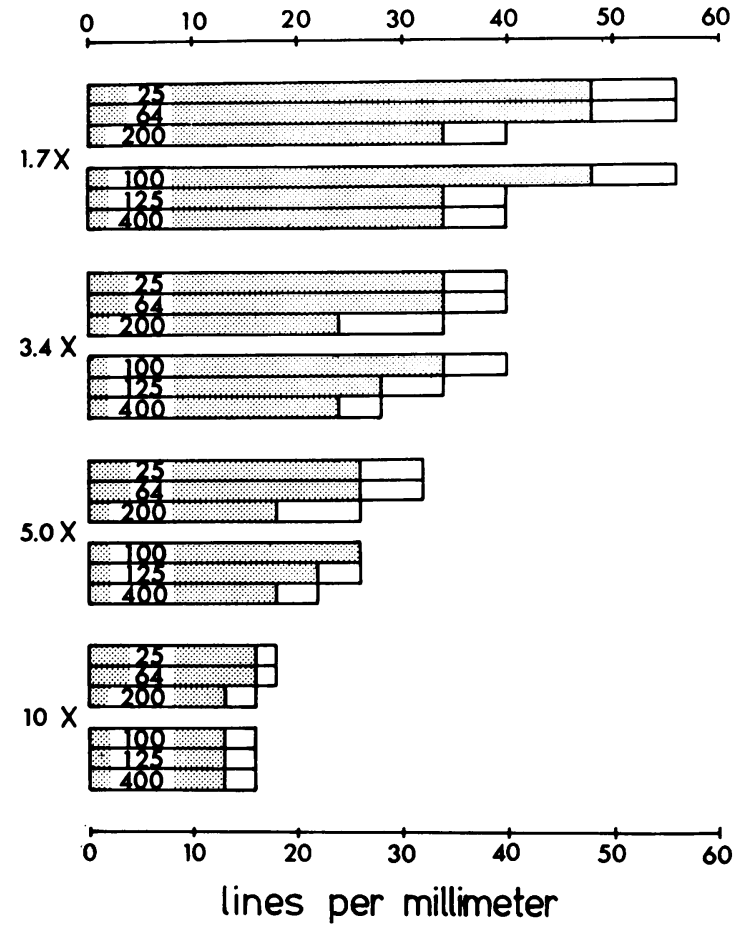

Fig. 2 Resolution obtained at high and low contrast levels with different films, with and without magnification attachments. The films are identified by their ASA values (cf. Table 1).

$20^{\circ} \mathrm{C}$, the other black-and-white films in Microdol $1+3$ according to the manufacturer's recommendations.

The results described here apply only to on-axis imagery. Off-axis imagery is more difficult to assess in a way meaningful to fundus photography. ${ }^{2}$

Colour diapositive fundus photographs. The 2 slower colour slide films showed highly similar results. The images were subjectively judged to be sharper and more finely detailed than those produced by Ektachrome 200. Kodachrome 64 appeared to be the film of choice for regular fundus photography. The best compromise between field size, resolution, and depth of focus, was obtained at the $3.4 \times$ magnification setting (Fig. 3A).

There was a more pronounced graininess in the slides obtained with filtered light. The green filtering did enhance the contrast of the nerve fibre layer to a moderate degree, but the simultaneous increase in image graininess tended to offset this advantage. It is possible that 'red-free' pictures of higher quality could have been obtained had only the fundus camera flash aggregate possessed a higher output. Within the limits of the available equipment, 


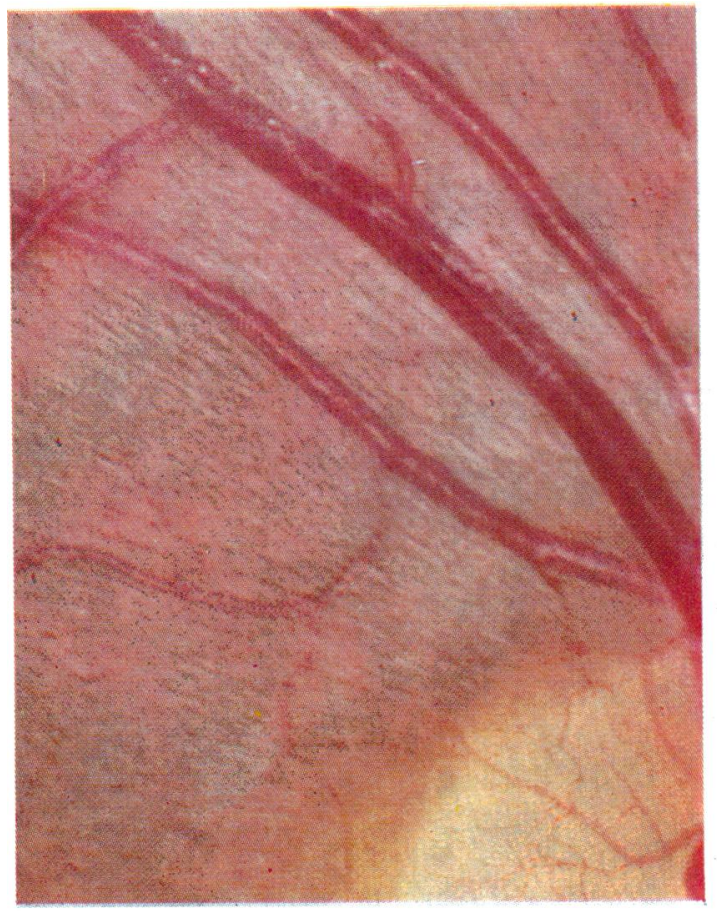

$3 A$

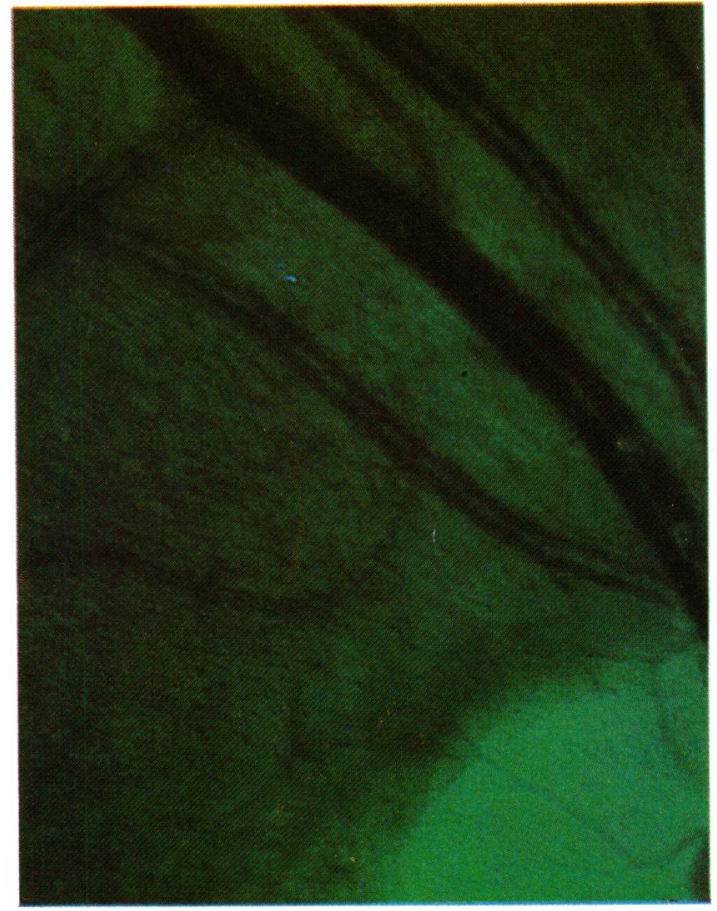

3B

Fig. 3 Appearance of part of the peripapillary retinal nerve fibre layer in one and the same normal fundus, using different types of films and filters. Nominal camera magnification $3.4 \times$, total magnification $40 \times$. A. Colour print from Kodachrome 64, exposed in white light. B. Colour print from Kodachrome 64, exposed in green light (Wratten No. 40). C. Print from Tri-X Pan negative, exposed in green light (Wratten No. 40). Photographic paper grade No. 4. D. Print from Plus-X Pan negative, exposed in green light (Wratten No. 40). Photographic paper grade No. 4. E. Print from Technical Pan negative, exposed in white light. Photographic paper grade No. 1. F. Print from Technical Pan contact copy of the Kodachrome 64 slide shown in Fig. 3A. The colour slide was exposed in white light, and the contact copy in green light (Wratten No. 65A). Photographic paper grade 1. The large change in paper grade between Technical Pan (Fig. 3F) and Tri-X Pan and Plus-X Pan (Figs. 3C, D) gives an indication of the difference in contrast in the different films: Technical Pan is much more contrasty than the other films. The black-and-white prints were all produced in a condenser-type enlarger, without manipulation of exposure, or retouching. 


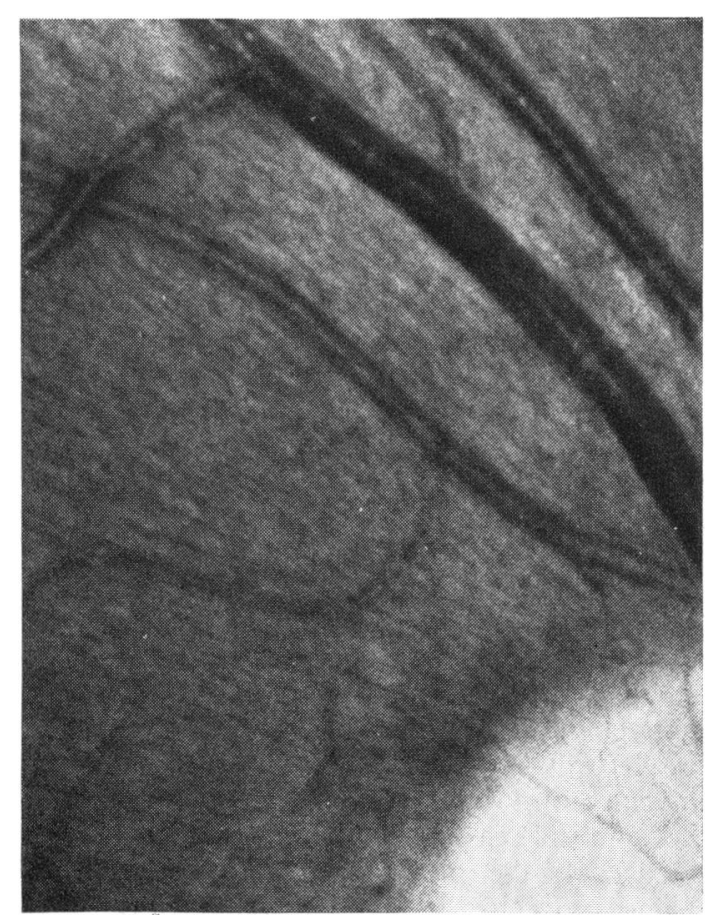

$3 C$

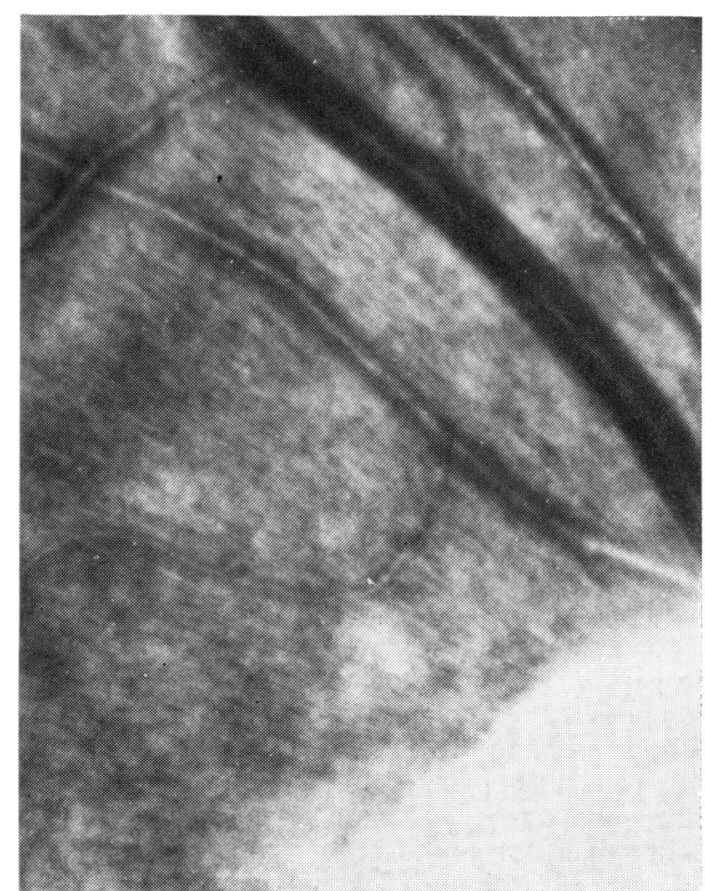

3E

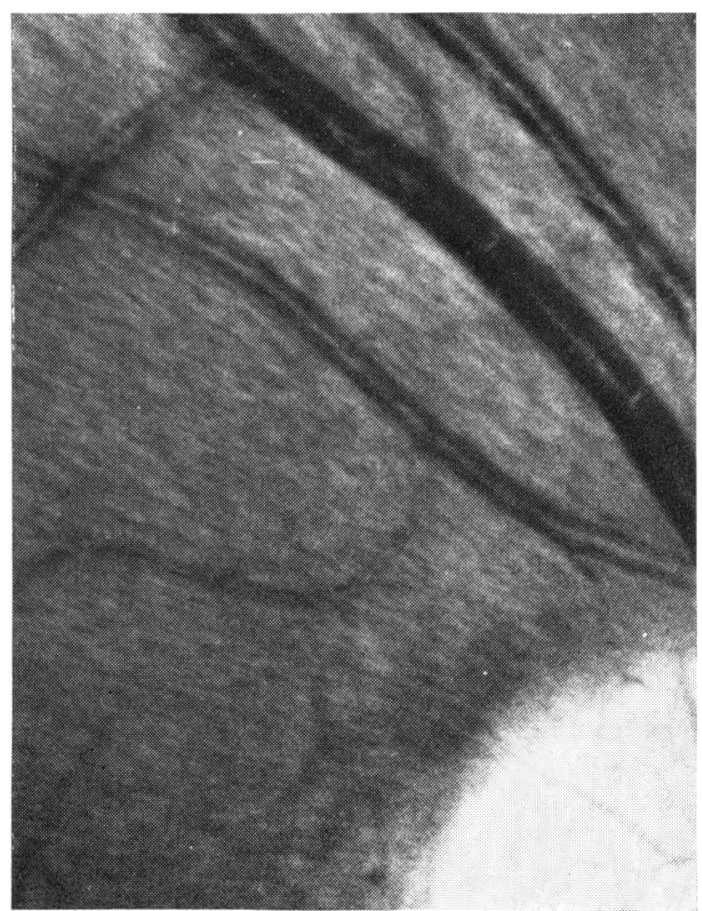

3D

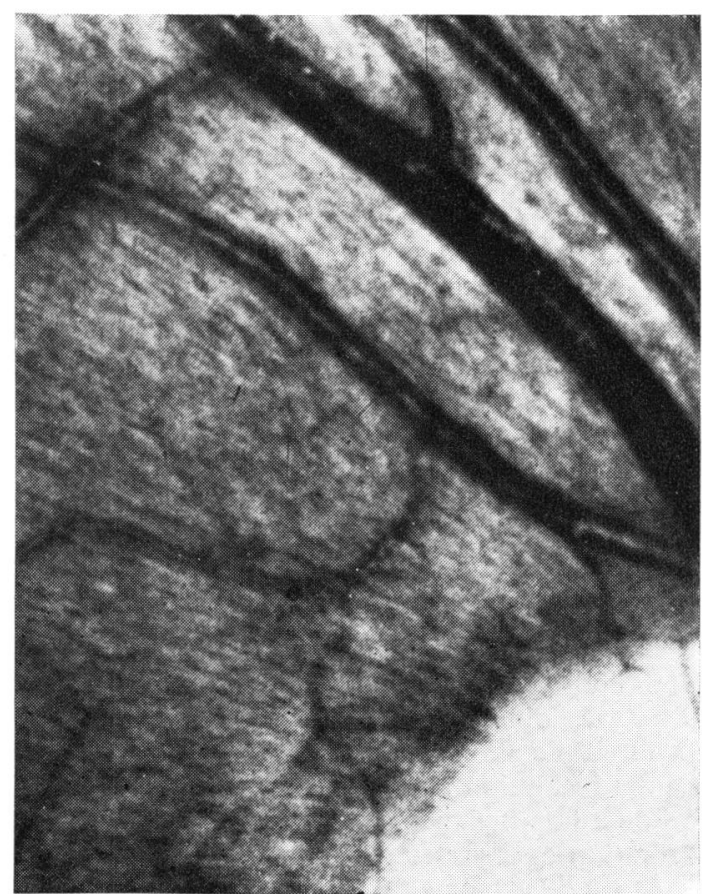

3F

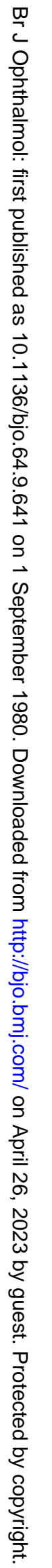


green filtering during photography with colour slide film appeared to have a limited value (Fig. 3B).

Black-and-white negative films in fundus photography. Two conventional black-and-white negative films were used in the fundus camera, namely Plux-X Pan and Tri-X Pan. As expected from the ratings (Table 1) and the results of the resolution study (Fig. 2), Plus-X Pan produced better detailed images of the peripapillary retinal nerve fibre layer, with a less disturbing graininess. With Plus-X Pan the visibility of the retinal nerve fibre layer was moderately enhanced when the Wratten No. 40 colour filter was introduced in the camera illumination beam. The effect was only marginal for Tri-X Pan (Figs. 3C and D). Three different developing procedures were tried with the Plux-X Pan film, namely Microdol $1+3$, overdevelopment $(15 \mathrm{~min})$ in undiluted Microdol, and D-11 $(1+1)$. The latter 2 produced more contrasty negatives but appeared to enhance granularity at the same time. The overall best results were obtained with the diluted Microdol developer.

Panatomic-X was not tried in the fundus camera because of its low light sensitivity.

The superiority of Technical Pan in the resolution study was not borne out at all magnification settings in fundus photography. Technical Pan has a higher sensitivity to red light than the other black-andwhite films, resulting in enhancement of the choroidal pattern and attenuation of nerve fibre contrast when using white illumination light (Fig. 3E). Filtering the illumination beam with the Wratten No. 40 green filter reduced exposure so much that severely underexposed negatives were obtained at magnifications higher than $1: 7 \cdot \times$. However, finely detailed and contrasty images with very little graininess were obtained at $1.7 \times$. At this setting the results were far superior to those obtained with the other 2 black-and-white films. The improved definition of peripapillary nerve fibre layer detail had to be traded against a poorer definition of details within the optic nerve head, however. This is due to the restricted exposure range of high contrast films (see further kelow).

One of the advantages with the Technical Pan negative film is that its contrast can be adjusted within wide limits, using different developers. HC-110 in different dilutions, and D-19 were tried. The best contrast within the retinal nerve fibre layer was obtained with $2 \mathrm{~min}$ of development in D-19, while longer development times led to impaired resolution and increased graininess. HC-110 produced softer negatives with a slightly better definition of disc detail.

At the $1.7 \times$ magnification setting Technical Pan at present appears to be the film of choice for black-and-white nerve fibre layer photography in green light. Unfortunately this film could not be used at higher magnifications, which often are necessary to obtain good resolution of fine nerve fibre detail. Plus-X Pan, developed in diluted Microdol, is a better black-and-white choice for higher magnifications.

Black-and-white copies of colour diapositives. The results described so far indicate that unfiltered colour slides constitute the best choice for ordinary fundus photography. Colour diapositive films produce natural-looking records with high resolution, extremely fine graininess, and a good contrast range. Their only disadvantage is the rather poor visibility of nerve fibre detail in comparison with filtered black-and-white films (Figs. 3A-D). A second stage production of contrast-enhanced black-and-white negatives from unfiltered colour diapositives could have several advantages, including: (1) elimination of the need to change film, filters, and illumination settings whenever nerve fibre records are desired; (2) elimination of the difficulties of focusing in faint, filtered light; (3) access in all cases to natural-looking primary records; (4) the possibility of processing slides obtained prior to the 'red-free era'; (5) the possibility of using low sensitivity films and low transmittance filters, without regard to the limited output power of fundus camera flash aggregates; and (6) freedom to chose films, filters, and developers on an individual basis in the seclusion of the darkroom.

Two methods of making black-and-white copies of unfiltered Kodachrome 64 slides were tried here.

A. Photographic reproduction at the 1:1 scale inevitably led to a loss of resolution. A variety of camera objectives were tried, mainly so-called macro- and microcamera objectives from major manufacturers, but also specialised reproduction objectives. The overall best results were obtained with a symmetrical apochromatic objective, namely, Rodenstock Apo-Rodagon $2 \cdot 8 / 50 \mathrm{~mm}$, at a working aperture of $5 \cdot 6$, on Technical Pan film. However, even with this objective and this film, there was a clear-cut loss in resolution when copying the slides from the resolution study (Table 2). Full resolution could be retained only by changing the scale of reproduction from $1: 1$ to $1 \cdot 25: 1$, or larger. But the gain in resolution on magnification was offset by undesired cropping. Copying at higher scales without cropping involves considerable expense.

B. Contact copying with the simple device described above (Fig. 1) produced consistently better results than 1:1 photographic copying (Table 2). This was true for all black-and-white films and all filters. Copies of fundus colour slides on Plux-X 
Table 2 Comparison of resolving powers in direct photography and copying

\begin{tabular}{|c|c|c|c|c|c|}
\hline Test & Kodachrome 64 & Tri-X Pan & Plus-X Pan & Panatomic- $X$ & Technical Pan \\
\hline $\begin{array}{l}\text { Resolution at } 1.7 \times \text { setting } \\
\text { in fundus camera at high/low } \\
\text { contrast levels (lines } / \mathrm{mm} \text { ) }\end{array}$ & $56 / 48$ & $40 / 34$ & $40 / 34$ & - & $56 / 48$ \\
\hline \multirow{2}{*}{$\begin{array}{l}\text { Resolution in black-and-white } \\
\text { copy of Kodachrome } 64\end{array}$} & & Photographic copy & $34 / 28$ & $40 / 34$ & $40 / 34$ \\
\hline & & Contact copy & $40 / 34$ & $48 / 40$ & $56 / 48$ \\
\hline
\end{tabular}

Pan and Panatomic-X were highly similar and could not consistently be told apart. There was little loss of resolution in the case of Panatomic-X, slightly more so on Plus-X Pan. Microdol $1+3$ was the best developer for both films. Overdevelopment in Microdol (15 min) and D-11 (1:1) produced better contrast but also a disturbing graininess. The very best results were obtained with Technical Pan, however. There was no detectable loss of resolution during contact copying on this film. Optimum nerve fibre layer contrast was obtained when developing for $2 \mathrm{~min}$ in D-19 (Fig. 3F).

Tri-X Pan was not of interest in this application because of its more pronounced graininess.

The various filters produced quite similar results with regard to nerve fibre bundle enhancement and differed primarily with regard to attenuation of choroidal detail. Wratten No. 65A and the interference filter produced equivalent negatives with good choroidal suppression; Wratten No. 40 admitted more choroidal detail, particularly in lightly pigmented fundi, making the definition of nerve fibre bundles somewhat softer.

In summary, contact copying unfiltered colour slides on Technical Pan, using Wratten No. 65A, and the D-19 developer, constitutes a simple and inexpensive technique for producing optimum nerve fibre bundle images, highly suitable as final records. The results produced in this way were considerably better than those obtained by the best technique for direct nerve fibre photography (Plus-X Pan exposed through Wratten No. 40, developed in Microdol $1+3$ ). The latter technique produced less contrasty and much more grainy images. These disadvantages were offset to some extent by a somewhat better reproduction of disc detail. The very best reproduction of disc detail was obtained in unfiltered colour diapositives, however. A maximum of information was therefore obtained by analysing, side by side, a colour slide together with a filtered Technical Pan contact copy.

Printing black-and-white negatives. Negatives produced on Plus-X Pan, Tri-X Pan, and Panatomic-X could in general be printed on photographic paper of grade 1 or 2 without resorting to dodging or burning-in. This was not always the case with the
Technical Pan negatives: these were often too contrasty to print well even on grade 1 photographic paper. For printing, negatives of such a large contrast need to be complemented with positive masks (masks with a reversed density distribution). Such a mask has the effect of compressing the range of contrast. If the mask is unsharp, it has the paradoxical effect of enhancing sharpness of small details. ${ }^{17}$ Unsharp masks are very useful also together with negatives of a more ordinary contrast range by virtue of the detailenhancing effect. They also allow use of higher grade photographic papers. ${ }^{14}$ Unsharp masks are most easily produced by photographic copying at the 1:1 scale on Technical Pan film, interposing an opaque material in between the original negative and the camera lens. The loss of resolution inherent in the photographic copying is irrelevant in this instant. Actually, the mask should be unsharp enough to be devoid of nerve fibre bundle detail. An underexposed mask produces the best results. Full details of this technique have been given elsewhere. $^{14}$

\section{Discussion}

The diameters of the individual axons that build up the retinal nerve fibre layer range normally between 0.6 and $2 \mu \mathrm{m} .{ }^{18}$ Fundus cameras cannot resolve such minute structures. Instead, photography depends on the convergence of axons on the peripapillary area, where the axons congregate densely enough to form a finely textured and slightly opaque layer that partially blurs out deeper structures. Texture is a surface characteristic. attributable to the formation of bundles of nerve fibres. These bundles continually change in diameter because of the tendency of individual axons to weave back and forth and up and down. ${ }^{19}$ Texture is therefore defined by extremely fine detail of low contrast. It is difficult to assign meaningful numerical values to texture and opacity, but it is clear that maximal resolution and maximal utilisation of contrast are required for successful nerve fibre layer photography. Therefore optimum results require precise focusing, maximum utilisation of contrast, and the use of a 


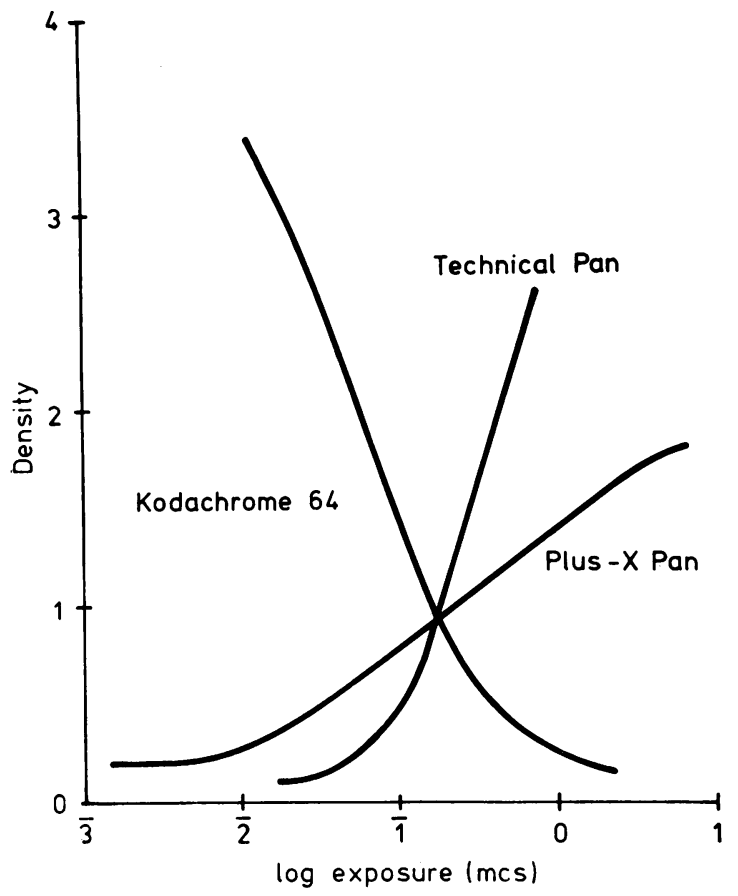

Fig. 4 Characteristic curves for some films used in this study. Redrawn from the manufacturer's data.

fine-grain film that does not fall short of the resolving power of the eye-and-camera system.

The optimum choice of film was extensively treated above and may need little additional comment here. But a few comments concerning high contrast films and their properties may be offered. In high contrast films the relationship between exposure and film density (the "characteristic curve' ${ }^{15}$ ) is much steeper than in ordinary films: a small increment in exposure causes a much larger increment in density. This effect is won by extending the useful density range, and compressing the useful exposure range (Fig. 4). Small differences in exposure, like those produced by adjacent nerve fibre bundles, cause only small variations in density in ordinary films. High contrast films amplify these small-scale variations, resulting in enhanced visibility of fine, low contrast detail. The gain in contrast has to be paid for. The restricted exposure range makes simultaneous recording of disc and nerve fibre detail somewhat difficult, and the images tend to become too contrasty to print directly (precisely as $x$-ray films). To avoid degradation in printing, high contrast films are best used as they are, i.e., as transparencies, and viewed under magnification. The restricted exposure range cannot be circumvented, however. Fortuitously, the best technique for producing high contrast nerve fibre layer records (copying unfiltered colour slides on to high contrast film, using filtered light) ensures availability of a natural-looking primary record. A maximum of information is obtained by analysing the colour slide and the nerve fibre transparency side by side.

Correct exposure is important for high quality photography. Both underexposure and overexposure lead to loss of information. Both high contrast black-and-white films and colour slide films are very sensitive to aberrations from correct exposure. It would be highly advantageous if the camera manufacturers could offer exposure sensing devices that could control the duration of the flash, akin to the automatic flash devices used for conventional photography. Limitation of illumination is desirable also for minimising the risk of retinal damage from light. Although the levels ordinarily used during fundus photography may fall short of critical levels, ${ }^{20}$ it is always sound to focus in the faintest, useful light, and to avoid low sensitivity films. Furthermore, excessive bleaching of rhodopsin impairs nerve fibre bundle contrast. ${ }^{21}$

Concerning resolution, little can be done to improve on existing fundus cameras, except for ensuring that the camera is clean, properly adjusted, and carefully focused. Focusing is a notorious problem in fundus photography. ${ }^{5}$ Instrumental aids have been described, but their value for photographing the nerve fibre layer" has not yet been explored. ${ }^{36}$ The difficulties of manual focusing are usually attributed to variations in the photographer's accommodation. While such variations undoubtedly may contribute to focusing difficulties, it appears more likely that the main problem is caused by the photographer's lack of knowledge of his degree of instrument myopia (or 'the intermediate dark focus of accommodation'22). The dark focus of accommodation can be determined only by using special equipment, but it is possible to obtain a good approximation in the following way. 1.7 D (=the average normal value of instrument myopia according to Leibowitz and Owens ${ }^{22}$ ) is subtracted from the photographer's refraction. The resulting value indicates the starting setting of the camera's ocular. After focusing in adequate light for a clear fundus image a few photographs are taken of one and the same eye at this ocular setting. Instrument myopia is then bracketed by refocusing and photographing after \pm 0.5 and $\pm 1.0 \mathrm{D}$ changes in ocular setting. Inspection of the photographs then shows the optimum setting of the ocular for future photography.

The depth of focus is inversely proportional to the degree of camera magnification. Although lower 
magnifications are more tolerant against focusing errors, higher magnifications give images with better detail. A good compromise between resolution, depth of focus, and size of field, seems to occur around 3 to $4 \times$.

Uncorrected astigmatism is detrimental to fundus photography. Even $0.5 \mathrm{D}$ of astigmatism produces noticeable blur. It is deplorable that most manufacturers of fundus cameras do not offer astigmatism compensation devices. Such devices are indispensable for good nerve fibre layer photography also in patients without astigmatism in central vision. Astigmatism arises as soon as the camera is disaligned with the optical axis of the eye. ${ }^{23}$ Such disalignment is usually required during photography of the peripapillary nerve fibre layer.

Discussions of ways and means for improving clinical nerve fibre layer photography have largely centered on the utility of various filters in the camera's illumination beam. To the casual ophthalmoscopist this may appear surprising, as the nerve fibre layer usually appears as a whitish or greyish structure. This layer apparently reflects light from all parts of the spectrum to about the same extent. Maximum information should then be retained by using full spectrum illumination. The earlier notion that the nerve fibre layer is opaque to light of short wavelengths ${ }^{72}$ has been refuted ${ }^{25}$ The rationale for filtering may relate to other factors, including nerve fibre layer translucency, and film properties. The relative enhancement of nerve fibre bundles in unfiltered black-and-white negatives, as compared to unfiltered colour slides, suggests that it is reddish retroillumination from deeper structures that attenuates the contrast of the nerve fibre layer in colour films. Most black-and-white films have a much poorer sensitivity in the red end of the spectrum than colour films. Filtering black-and-white films with a Wratten No. 40 gelatin filter enhances definition of the nerve fibre layer in proportion to the film's sensitivity to red: the effect is only marginal for Tri-X Pan, more pronounced for Panatomic-X and Plus-X Pan, and dramatic for Technical Pan. As mentioned above, the precise characteristics of the filter appear to be relatively unimportant. An expensive interference filter is not necessarily better than a simple gelatin filter. Orthochromatic films may need no filtering at all. ${ }^{12}$

The optimisations analysed in this study do not solve all the problems associated with clinical photography of the retinal nerve fibre layer. Patients with optical imperfections, thinner than normal nerve fibre layers, or a poor background pigmentation, still remain difficult to photograph. It is difficult to see ways of circumventing these problems. The texture of the retinal nerve fibre layer could possibly be enhanced by using indirect illumination. Fundus cameras with better resolving powers might be of aid. Holographic photography, ${ }^{26}$ special methods of film development, ${ }^{13}$ optical contrasting, ${ }^{27}$ and computerised spatial frequency filtering ${ }^{28}$ might also prove useful.

This study was supported by Marianne och Marcus Wallenbergs Stiftelse, and the University of Göteborg. I am deeply grateful to Ms Britt-Marie Johansson and Ms Lena Kjällman for patient help, to $\mathrm{Mr} \mathrm{L}$. Grandell of $\mathrm{A}$. V. Bergström Instrument $\mathrm{AB}$ for loan of reproduction lenses, and to $\mathrm{Mr}$ P.-A. Ekberg of Kodak AB for expert advice.

\section{References}

1 Hirano A, Takahasi T. Resolving power of fundus cameras. Jpn J Clin Ophthalmol 1971; 25: 2285-7.

2 Frisén L. Resolution at low contrast with a fundus camera. Comparison of various photographic films. Invest Ophthalmol 1973; 12 : 865-9.

3 Laing RA, Danisch LA. An objective focusing method for fundus photography. Invest Ophthalmol 1975; 14: 329-33.

4 Bracher D, Lotmar W, Bossi E, Vassella F. Fundus photography in neonates, an approach to obtain indirect information on cerebral blood flow. Helv Paediatr Acta 1975; 30: 473-86.

5 Allen L. Ocular fundus photography. Suggestions for achieving consistently good pictures and instructions for stereoscopic photography. Am J Ophthalmol 1964; 57: 13-28.

6 Bengtsson B, Krakau CET. A simple routine for optic disc photography through a natural pupil. Short communication. Acta Ophthalmol 1979; 57: 151-4.

7 Behrendt T, Wilson LA. Spectral reflectance photography of the retina. Am J Ophthalmol 1965; 59: 1079-88.

8 Mizuno $\mathrm{K}$, Ozawa $\mathrm{K}$, Ito $\mathrm{H}$. High magnification red-free light fundus photography. Mod Probl Ophthalmol 1971; 9: $50-4$.

9 Delori FC, Gragoudas ES, Francisco R, Pruett RC. Monochromatic ophthalmoscopy and fundus photography. The normal fundus. Arch Ophthalmol 1977; 95: 861-8.

10 Miller NR, George TW. Monochromatic (red-free) photography and ophthalmoscopy of the peripapillary retinal nerve fiber layer. Invest Ophthalmol 1978; 17: $1121-4$.

11 Ducrey NM, Delori FC, Gragoudas ES. Monochromatic ophthalmoscopy and fundus photography. II. The pathological fundus. Arch Ophthalmol 1979; 97: 288-93.

12 Craandijk A, Aan de Kerk AL. Retinal photography using panchromatic and ortochromatic films. $B r J$ Ophthalmol 1969; 53: 568-7.

13 Meinel U, Högner W. Erhöhte Informationsgewinnung durch kontrastgesteurte Fundusphotographien. Klin Monatsbl Augenheilkd 1974; 165: 886-91.

14 Frisén L, Hoyt WF. Unsharp masking in fundus photography. Invest Ophthalmol 1973; 12: 461-4.

15 Washer FE, Gardner IC. Method for determining the resolving power of photographic lenses. National Bureau of Standard Circular 533. Washington: U.S. Government Printing Office, 1953.

16 McCamy CS. The evaluation and manipulation of photographic images. In: Lipkin BS, Rosenfeld A, eds. Picture Processing and Psychopictorics. New York: 
Academic Press, 1970.

17 Yule JAC. Unsharp masks. Photogr Soc Am J 1945; 2: 123-32.

18 Villegas GM. Ultrastructure of the human retina. J Anat 1964; 98: 501-13.

19 Ogden TE. The nerve-fiber layer of the primate retina: an autoradiographic study. Invest Ophthalmol 1974; 13: 95-100.

20 Lanum J. The damaging effect of light on the retina. Empirical findings, theoretical and practical implications. Surv Ophthalmol 1978; 22: 221-49.

21 Mizuno K, Majima A, Ozawa K, Ito H. Red-free light fundus photography. Photographic optogram. Invest Ophthalmol 1968; 7: 241-9.

22 Leibowitz HW, Owens DA. Anomalous myopias and the intermediate dark focus of accommodation. Science 1975; 189: 676-8.
23 Lotmar W, Lotmar T. Peripheral astigmatism in the human eye: experimental data and theoretical model predictions. J Opt Soc Am 1964; 65: 510-3.

24 Behrendt T, Duane TD. Investigation of fundus oculi with spectral reflectance photography. Arch Ophthalmol 1966; 75: 375-9.

25 Cullen AP. Fundus examination with restricted spectrum light. Am J Optom Physiol Opt 1971 ; 48: 803-10.

26 Olson LE, Hershkowitz N, DeKock JR. Ophthalmic holography. In: Blodi FC, ed. Current Concepts in Ophthalmology. Saint Louis: Mosby, 1974: 4.

27 Cloupeau M. The printing of underexposed photographs by means of 'optical contrasters'. Photogr Sci Engineering 1961; 5: 175-80.

28 Nathan R. Spatial frequency filtering. In: Lipkin BS, Rosenfeld A, eds. Picture Processing and Psychopictcrics. New York: Academic Press, 1970. 